\title{
Ameliorated and antioxidant effects of Fucoidan against cyclosporine A-induced kidney injury in rats
}

\author{
Bushra Y. H. Al-Khatib*, Nada M. H. Al-Hamdani and Hussein S. A. Gumaih
}

\begin{abstract}
Background: Cyclosporine A (CSA) is an immunosuppression agent used frequently in fields of organs transplantation and autoimmune diseases. However, CSA-induced kidney injury is a major clinical problem associated with CsA therapy in which the conceivable accountable mechanism is oxidative stress (OS). The present study evaluated the protective and ameliorated effects of fucoidan (FU) as an antioxidant and an anti-inflammatory agent against CsA-induced kidney injury.
\end{abstract}

Methods: Male rats were randomly divided into three groups. The first group was served as a control group that administered olive oil orally and normal saline subcutaneously, the second group (CA) was treated with CsA orally, and the third group $(\mathrm{CA}+\mathrm{FU})$ was treated with CsA orally in concomitant with FU subcutaneously. Experimental animals were sacrificed 20 days following the treatment period and serum samples were analyzed for creatinine test. The homogenate of renal tissues was prepared for OS assessment. Light and ultrastructure microscopic kidney sections were prepared for histopathological examination.

Results: Treatment of rats with CSA alone produced a significant increase in the levels of creatinine, nitric oxide (NO), and malondialdehyde (MDA), as well as the activities of superoxide dismutase (SOD), catalase (CAT), and glucose 6 phosphate dehydrogenase (G6PD), whereas the level of glutathione reduced (GSH) was decreased. Some histopathological changes of the kidney tissue including tubular epithelial hypertrophy, vacuolizations, necrotic glomerulus cell, capillaries network shrinking, vascular congestion, interstitial infiltration, loss of apical microvilli, and deteriorated mitochondria were observed in CA group. Concomitant FU administration with CsA enhanced renal function, as indicated by the low level of creatinine. Moreover, FU ameliorated the oxidative status in kidney tissue as well as it provided histological protection against CsA-induced kidney injury.

Conclusion: FU can develop a protective mechanism against kidney injury induced by CsA that mediated by OS.

Keywords: Kidney, Cyclosporine, Fucoidan, Oxidative stress, Semithin, Ultrastructure

\section{Background}

Cyclosporine A (CsA) is one of the calcineurin inhibitors that is widely used as immunosuppressive therapy in areas of organs transplantation and autoimmune diseases especially dermal diseases and inflammatory diseases such as rheumatoid arthritis, psoriasis, and atopic dermatitis (Harper, Berth-Jones, Camp, Dillon, Finlay, Holden, O'Sullivan, \& Veys, 2001; Tedesco \& Haragsim, 2012). CsA has a specific effect on T-lymphocytes in which it inhibits the

\footnotetext{
*Correspondence: alkhateeb.bushra@gmail.com

Biology Department, Faculty of Science, Sana'a University, Sana'a, Yemen
}

receptor signal transduction pathway that consequently blocks interleukin 2 syntheses (Ho, Clipstone, Timmermann, Northrop, Graef, Fiorentino, Nourse, \& Crabtree, 1996; Matsuda \& Koyasu, 2000).

However, CsA has some dose-related adverse effects including nephrotoxicity, hepatoxicity, and splenic injury (De Mattos, Olyaei, \& Bennett, 2000; Herrero, Quiroga, Sangro, Beloqui, Pardo, Cienfuegos, \& Prieto, 2000; Omar, Eldien, Badary, Al-Khatib, \& Abd Elgaffar, 2013). Acute nephrotoxicity is concomitant with a high blood level of CsA and a rapid upsurge in renal function tests that associated with vasospasm of afferent 
arteriole but this toxicity is inverted with drug dose reduction (Barros, Boim, Ajzen, Ramos, \& Schor, 1987; Laskow, Curtis, Luke, Julian, Jones, Deierhoi, Barber, \& Diethelm, 1990; Slattery, Campbell, McMorrow, \& Ryan, 2005). In contrast, chronic nephrotoxicity is occurred in continued exposure to a lower level of CsA and does not recover after dose reduction (Slattery et al., 2005). In addition, the effect of CsA treatment on nephrotoxicity, kidney lesions, and creatinine level have been documented by Elsayed, Bayomy, and Azab (2016), Gökçe et al. (2009), and Mansour, Daba, Gado, Al-Rikabi, and Al-Majed (2002).

Reactive oxygen species (ROS) have been employed in the CsA toxicity either by direct action or by the motivation of lipid peroxidation (Durak et al., 2002; Inselmann et al., 1994). The protective role of different antioxidants has been estimated on CsA-induced nephrotoxicity. As reported in previous studies, when antioxidants utilized on the kidney, they can enhance the morphological and the cyto-histological structure of tissue as well as can increase the antioxidants levels and decrease the peroxidation and ROS levels (Anjaneyulu et al., 2003; Ebru et al., 2011; Uz et al., 2008). The protecting role of antioxidants is confirmed also on CsA hepatotoxicity (Rezzani, 2006).

Ocean brown algae are considered as one of the most valuable natural sources against many animal body syndromes. Meanwhile, sulfated polysaccharides, which profusely found in brown algae, possessed wide pharmacological actions, especially as antioxidants agents and potent free radical scavengers. (Park et al., 2005; Xue et al., 2001). Fucoidan (FU), a polysaccharide purified from brown algae such as Fucus vesiculosus, is comprised of extensive proportions of L-fucose and sulfate ester groups. FU has been extensively studied due to its varied biological properties in which it acts as an anticoagulant, antithrombotic, anti-inflammatory, antitumor, immunomodulatory, anti-complementary and antivirus agents, as well as it acts to reduce the blood lipids (Bilan et al., 2002; Li et al., 2008). Further, FU ameliorated the changes of bone marrow cells induced by CsA treatment (Eldien et al., 2012) and expressed activities against hepatopathy, uropathy, and kidney harms as well as it has a gastric protective effect (Kwak, 2014; Li et al., 2008). In addition, FU can inhibit the synthesis and release of ROS as well as it promotes its clearance that proved its antioxidative activity (Balboa et al., 2013; Josephine et al., 2008).

The main purpose of this study was to investigate the ameliorated and the protective effects of FU on CsA-induced kidney injury through assessing the change in the level of creatinine in serum, as an indicator of kidney injury, and the changes in the levels of some oxidative stress parameters (MDA, NO, GSH, SOD, CAT, and G6PD) as well as by studying the histopathological aspects in kidney tissue, either with FU treatment or not.

\section{Materials and methods}

\section{Chemicals and reagents}

Cyclosporine A, Neoral Oral Solution, was present as a clear, yellow liquid supplied in $50 \mathrm{~mL}$ bottles containing $100 \mathrm{mg} / \mathrm{mL}$ (NDC 0078-0274-22). It is distributed by Novartis Pharmaceuticals Corporation, East Hanover, New Jersey 07936. Fucoidan from Fucus vesiculosus. It was purchased from Sigma Chemicals, St. Louis, MO, USA. All other chemicals and reagents were of the highest purity commercially available.

\section{Animals and experimental procedures}

In the present study, 24 male albino rats weighing between 150 and $200 \mathrm{~g}$ were obtained from the Animal House of the Faculty of Medicine, Assiut University. They were housed in polypropylene cages (eight animals per cage) containing husk as the bedding material. The whole experiment was carried out at the same environmental conditions at a room temperature of $30 \pm 5{ }^{\circ} \mathrm{C}$ under $12 \mathrm{~h}$ light and $12 \mathrm{~h}$ dark schedule. The animals had ad libitum excess of pelleted diet ( $80 \%$ carbohydrates, $2 \%$ fats, and $18 \%$ proteins in addition to an appropriate quantity of vitamins) and water throughout the experimental period. Animals were kept, in the room of treatment, 7 days prior to the experiment as adaptation period and the bedding of the animal cages changed every $48 \mathrm{~h}$. All experiments followed protocols permitted by the Institutional Animal Care and Life Committee, Assiut University. The number of animals in our experiment has been carefully selected from the outset to avoid unnecessary increases and the treatment was done as gently as possible to avoid pain. Also, an appropriate quantity of anesthesia was used at the time of dissection. The Guidelines for Ethical Conduct in the Care and Use of Animals provided by American Association of Psychologists was followed as possible as, beside Assiut University protocol.

Experimental animals were randomly divided into three groups of eight rats each as follows:

\section{The first group (C)}

Daily received an oral dose of $2 \mathrm{~mL} / \mathrm{kg}$ BW olive oil and a subcutaneous dose of $2 \mathrm{~mL} / \mathrm{kg}$ BW normal saline for 20 days and served as control.

\section{The second group (CA)}

Daily received an oral dose of CsA (25 mg/kg BW) dissolved in $2 \mathrm{~mL} / \mathrm{kg}$ BW olive oil for 20 days, according to Josephine, Veena, Amudha, Preetha, and Varalakshmi (2006).

\section{Third group (CA + FU)}

Daily received an oral dose of CsA $(25 \mathrm{mg} / \mathrm{kg} \mathrm{BW})$ dissolved in $2 \mathrm{~mL} / \mathrm{kg}$ BW olive oil concomitant with 
subcutaneous administration of $\mathrm{FU}(5 \mathrm{mg} / \mathrm{kg} \mathrm{BW})$ that dissolved in $2 \mathrm{~mL} / \mathrm{kg} \mathrm{BW}$ saline for 20 days, according to Veena, Josephine, Preetha, Varalakshmi, and Sundarapandiyan (2006).

At the end of the experimental period, all animals were sacrificed by cervical decapitation and blood samples were collected into sterilized tubes for serum creatinine level assay. Samples of kidneys were immediately excised and rinsed in $(0.1 \mathrm{M})$ phosphate buffer $(\mathrm{pH} 7.4)$ then stored at $-20{ }^{\circ} \mathrm{C}$ for biochemical studies. Small sizes of kidneys tissue were quickly removed, washed, and fixed immediately in $4 \%$ cold glutaraldehyde for semithin and ultrastructure studies. Other kidney's pieces were fixed in $10 \%$ neutral-buffered formalin, for the histopathological study under a light microscope using hematoxylin-eosin staining.

\section{Biochemical estimations}

\section{Serum and tissue homogenate preparation}

Blood samples were centrifuged at $4000 \mathrm{rpm}$ for $10 \mathrm{~min}$ to separate the serum which kept frozen at $-20{ }^{\circ} \mathrm{C}$. For kidneys tissue homogenate preparation $(10 \% w / v)$, $500 \mathrm{mg}$ of each kidney tissue was homogenized in $5 \mathrm{~mL}$ phosphate buffer $(0.1 \mathrm{M}, \mathrm{pH}$ 7.4) using homogenizer (IKA Yellow line DI 18 Disperser, Germany) then homogenates were kept frozen at $-20{ }^{\circ} \mathrm{C}$ for the subsequent biochemical assay.

\section{Measurement of the biochemical parameters}

Renal injury was assessed through a serum creatinine level was determined colorimetrically using commercial kits according to the procedure of Young (1990) and expressed as $\mathrm{U} / \mathrm{L}$.

Homogenization of kidney tissues was done to determine the renal oxidative stress and antioxidants levels. Protein content in kidney tissues was determined according to Lowry, Rosebrough, Farr, and Randall (1951). Malondialdehyde (MDA) as the end product of lipid peroxidation was assessed according to Ohkawa, Ohishi, and Yagi (1979). Nitric oxide (NO) content was measured as a nitrate concentration using the method of Ding, Nathan, and Stuehr (1988). Glutathione reduced (GSH) content was determined using the method of Beutler (1963). The activity of superoxide dismutase (SOD) was determined to base on its ability to inhibit the autoxidation of epinephrine at alkaline medium according to the method of Misra and Fridovich (1972). The activity of catalase (CAT) was determined to base on its ability to decompose $\mathrm{H}_{2} \mathrm{O}_{2}$ to $\mathrm{H}_{2} \mathrm{O}$ and $\mathrm{O}_{2}$ according to Beers and Sizer (1952). G6PD activity was assessed depended on its ability to reduce NADP level according to Tsai and Chen (1998).

\section{Histopathological evaluation \\ Light microscopic study \\ Hematoxylin-eosin staining}

After the fixation in $10 \%$ formalin, kidney pieces were processed to prepare 5 - $\mu$-thick paraffin sections then stained with hematoxylin and eosin (Bancroft \& Gamble, 2008) and microscopically examined.

\section{Toluidine blue staining}

Kidney pieces, which fixed in glutaraldehyde (4\%), were washed in cacodylate buffer $(0.1 \mathrm{M}, \mathrm{pH} 7.2)$ for $1-3 \mathrm{~h}$ then post-fixed in $1 \%$ osmium tetraoxide for $2 \mathrm{~h}$. After that, specimens were washed repeatedly in cacodylate buffer and dehydrated in ascending grades of ethyl alcohol up to $100 \%$. Specimens were placed in propylene oxide for $60 \mathrm{~min}$, then in pure epon 812 and incubated in a special polymerization incubator to make blocks (first day at $35{ }^{\circ} \mathrm{C}$, the second day at $45{ }^{\circ} \mathrm{C}$, and third day at $60{ }^{\circ} \mathrm{C}$ ), blocks were approximately $1 \times 1 \times 1 \mathrm{~mm}$. They were trimmed with LKB ultratom. Semithin sections of $0.5 \mu \mathrm{m}$ thickness were stained with toluidine blue for 2 min at $80{ }^{\circ} \mathrm{C}$ (Gupta, 1983) and examined under a light microscope.

\section{Ultrastructure microscopic study}

Representative fields of semithin sections were selected. Ultrathin sections $(70 \mathrm{~nm})$ were cut with a diamond knife using a Reichert OMVs ultramicrotome. They were mounted in copper grids and stained with uranyl acetatelead citrate stain. The ultrastructure investigation was according to Bancroft and Gamble (2008) and carried out at Electron Microscopic Center, Assiut University, with transmission electron microscope (TEM) (Joel Cx II).

\section{Statistical analysis}

The results were analyzed by one-way analysis of variance (ANOVA) followed by Newman-Keuls multiple comparison test as post-test by using Prism program for Windows, version 6 (Graph Pad software, Inc., San Diago CA. USA). The significant difference between groups was accepted at $p<0.05,<0.001$, and $<0.001$.

\section{Results \\ Biochemical estimations result Serum creatinine level}

Cyclosporine A-induced kidney injury in experimental rats that was demonstrated by a significant elevation of serum creatinine level when compared with that in the control group $(p<0.001)$ as shown in Fig. 1 , whereas FU concomitant treatment with CsA caused a significant decrease in this level as compared to CA group $(p<0.01)$. 


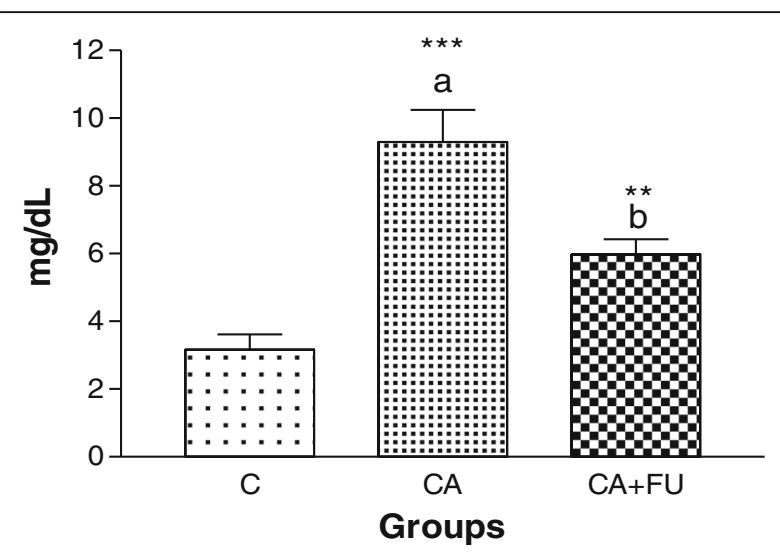

Fig. 1 Effect of treatment with cyclosporine and fucoidan on serum creatinine level. C control group, CA cyclosporine group, CA + FU cyclosporine + fucoidan group. The significant difference between groups was judged by ANOVA as follows: $\mathrm{a}=$ significance difference between $C$ and $C A, b=$ significance difference between $C A$ and $C A$ $+\mathrm{FU} ;{ }^{*} p<0.05 ;{ }^{* *} p<0.01 ;{ }^{* * *} p<0.001$

\section{Oxidative stress and antioxidants levels}

As shown in the Table 1, CsA produced changes in kidney oxidative statue. It caused a significant increase in MDA content compared to the control group $(p<0.01)$, whereas FU in group CA + FU partially declined this level compared to CA group (\% of inhibition $=15.14)$. However, both CsA treatment alone and CsA with FU treatment caused high increased in NO level of kidney tissue when compared to the control group $(p<0.001)$ with a higher percentage of NO production in CA group compared to CA + FU group (155.172 and 120.689, respectively). Kidney GSH content was slightly declined by CsA treatment, while CsA + FU treatment significantly increased GSH production when compared to both C and CA groups $(p<0.05)$. In addition, the treatment with CsA alone resulted in an increase in the levels of SOD, CAT, and G6PD of kidney tissue, while concurrent treatment with both CsA and FU caused more increasing in these antioxidant levels except that of CAT level when compared to CA group.

\section{Histopathological evaluation}

\section{Light microscopic examination}

Hematoxylin and eosin staining

As shown in Fig. 2, sections of renal cortex in control group illustrated a healthy appearance. Intact Malpighian corpuscles were present with glomerulus surrounded by a normal capsular space that followed by Bowman's capsule epithelial. Furthermore, the structure of renal tubules (proximal and distal convoluted tubules) was mostly normal with intact cuboidal cells (Fig. 2a). However, the examination of kidney sections of CA group revealed many degenerated changes such as some hypertrophic Malpighian corpuscles characterized by a reduction of Bowman's spaces and adhesion between the glomerular tuft and the capsule (Fig. 1b). Additionally, a high degree of degeneration was found in many renal tubules (Figs. 2c, d) in which some of the apical surfaces had a rupture. Also, cells of some tubules showed vacuolization, necrotic nuclei, fatty change, and a high degree of hydropic change. Lumen obliteration was observed in some tubules. In contrary, sections of CA + FU group illustrated an improvement in the histological structure of the kidney tissue as a appeared in Fig. 2e, whereas there was some remarked degeneration like that of the glomerulus.

\section{Toluidine blue staining}

Control group toluidine blue sections (Fig. 3a) revealed a normal and integral composed of kidney glomerulus and tubules. However, CA group kidney sections showed many degenerated signs as seen in Figs. 3b, c and $4 a-c$ in which many necrotic glomerulus cells were present with dense, contracted, and degenerated nuclei. Also, the capillaries network showed shrinkage that caused extension of spaces inside the glomeruli as well as some parts of the capillaries wall were destructed and/or thickened. Also, some parts of Bowman's capsules degenerated. The epithelial lining of the proximal tubules was observed with some degenerated manners such as a high degree of the cytoplasmic vacuolization, destructed of the apical brush border, and necrotic

Table 1 Malondialdehyde, nitric oxide, and some antioxidants levels in the renal homogenate of rats treated with CSA and FU

\begin{tabular}{|c|c|c|c|c|c|c|c|}
\hline $\begin{array}{l}\text { Biomarkers } \\
\text { Group }\end{array}$ & Statistic & $\begin{array}{l}\text { MDA (nmol/ } \\
\text { mg protein) }\end{array}$ & $\begin{array}{l}\mathrm{NO} n m o l / m g \\
\text { protein }\end{array}$ & $\begin{array}{l}\text { GSHug/mg } \\
\text { protein }\end{array}$ & $\begin{array}{l}\mathrm{SOD} \mathrm{U} / \mathrm{min} / \\
\mathrm{mg} \text { protein }\end{array}$ & $\begin{array}{l}\text { CAT U/min/ } \\
\text { mg protein }\end{array}$ & $\begin{array}{l}\text { G6PD U/ } \\
\mathrm{min} / \mathrm{mg} \\
\text { protein }\end{array}$ \\
\hline$C$ & Mean \pm SE $(n=8)$ & $2.06 \pm 0.20$ & $0.116 \pm 0.01$ & $1.583 \pm 0.06$ & $2.006 \pm 0.12$ & $17.68 \pm 0.56$ & $0.19 \pm 0.02$ \\
\hline \multirow[t]{2}{*}{ CA } & Mean \pm SE $(n=8)$ & $3.70 \pm 0.325$ & $0.30 \pm 0.02$ & $1.47 \pm 0.11$ & $2.28 \pm 0.13$ & $20.75 \pm 1.13$ & $0.27 \pm 0.02$ \\
\hline & I or $\mathrm{S} \%$ vs C & $S=78.87 a^{* *}$ & $S=16.17 a^{* * *}$ & $\mathrm{I}=9.34 \mathrm{NS}$ & $S=13.66 \mathrm{NS}$ & $S=17.36 \mathrm{NS}$ & $S=40.211 \mathrm{NS}$ \\
\hline \multirow[t]{3}{*}{$C A+F U$} & Mean \pm SE $(n=8)$ & $3.13 \pm 0.25$ & $0.256 \pm 0.02$ & $1.872 \pm 0.05$ & $2.47 \pm 0.08$ & $20.51 \pm 0.29$ & $0.29 \pm 0.04$ \\
\hline & I or $\mathrm{S} \%$ vs C & $S=51.792 a^{*}$ & $S=120.689 a^{* * *}$ & $S=14.839 * a$ & $S=22.931 \mathrm{NS}$ & $S=16.006 \mathrm{NS}$ & $\mathrm{S}=53.439 \mathrm{NS}$ \\
\hline & I or $\mathrm{S} \% \mathrm{vs} C A$ & $\mathrm{I}=15.140 \mathrm{NS}$ & $I=13.513 \mathrm{NS}$ & $S=6.070 a^{*}$ & $S=8.157 \mathrm{NS}$ & $\mathrm{I}=1.156 \mathrm{NS}$ & $S=9.43 \mathrm{NS}$ \\
\hline
\end{tabular}

C control group, $C A$ Cyclosporine group, $C A+F U$ cyclosporine + fucoidan group. The significant difference between groups was judged by ANOVA. a: significance difference between the groups, ${ }^{*} p<0.05 ;{ }^{* *} p<0.01$; ${ }^{* *} p<0.001$; NS non-significant, (vs C): percentage of difference with control group, (vs CA): percentage of difference with cyclosporine $A$ group. I inhibition, $S$ stimulation 


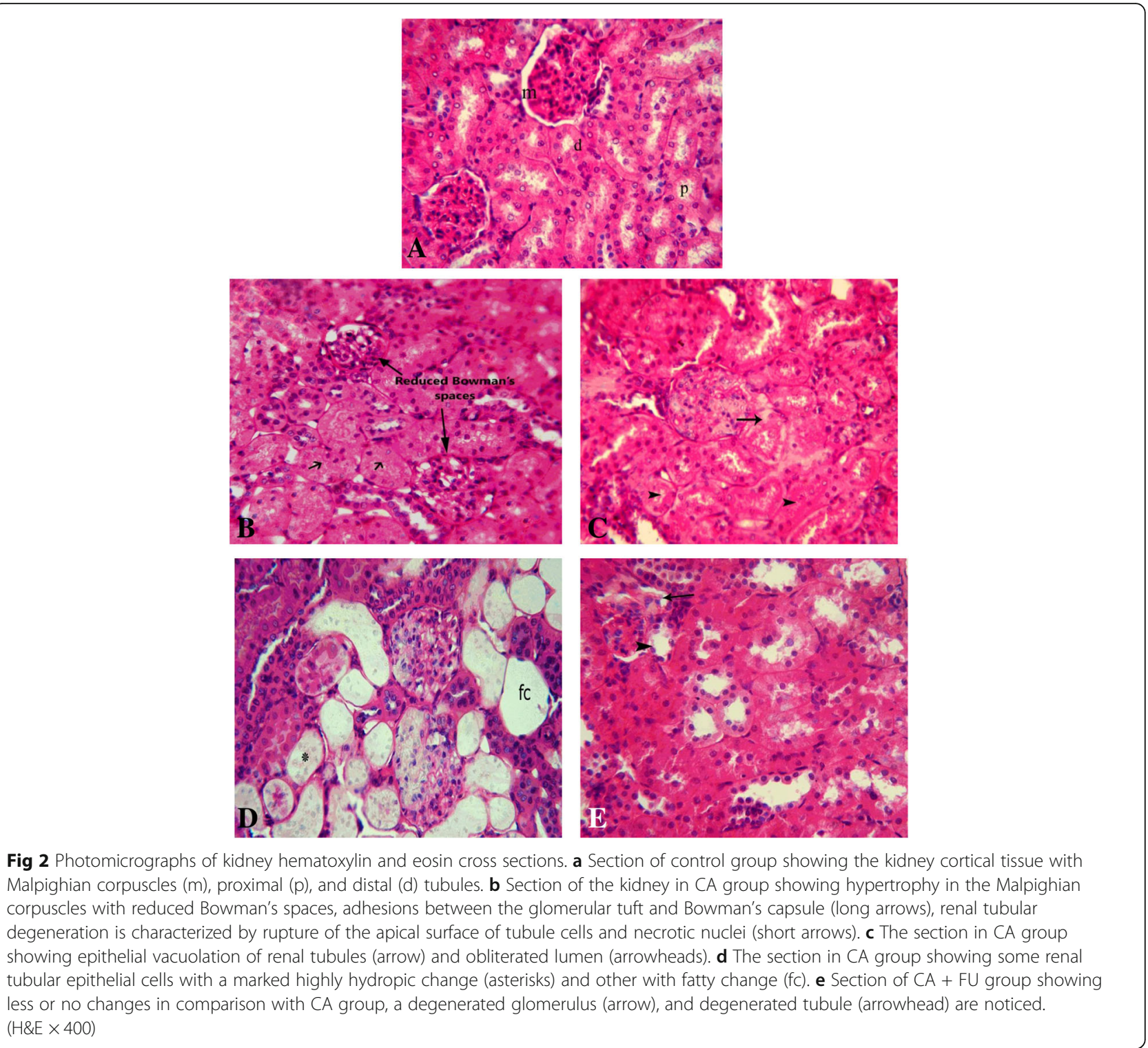

changes of nuclei. This group also showed a high degree of vascular congestion and interstitial infiltration. In contrast, FU co-treatment with CsA resulted in an ameliorate of the kidney tissue structure with a low degree of the degenerated; instead, it was more like sections in control group, in both glomeruli and tubules as shown in Figs. 3d and 4d.

\section{Ultrastructure microscopic result}

As shown in Fig. 5a, the ultrastructure sections of the kidney proximal tubules in control group illustrated a normal nucleus characterized by a marginally arranged chromatin material. An integral cytoplasm was observed with intact mitochondria as well as the microvilli were long and dense. However, sections of the CA group (Fig. 5b) showed many degenerated changes such as a loss of the apical microvilli and a thickening of the basement membrane as well as some degenerated nuclei had a regressive size and high dense chromatin. This group also revealed rarefied cytoplasm that included some deteriorated mitochondria with destructed cristae. In comparing with CA group, ultrastructure sections in CA + FU group (Fig. 5c) demonstrated a partial ameliorated in the cells of the proximal tubule in which many nuclei were normal arranged and the apical microvilli were partially long and dense. In addition, there were some rarefied parts of the cytoplasm beside the healthy parts.

\section{Discussion}

Cyclosporine $\mathrm{A}$ is an immunosuppressive drug used universally for its potent action. But, unfortunately, its clinical uses are related with some adverse side effects such 

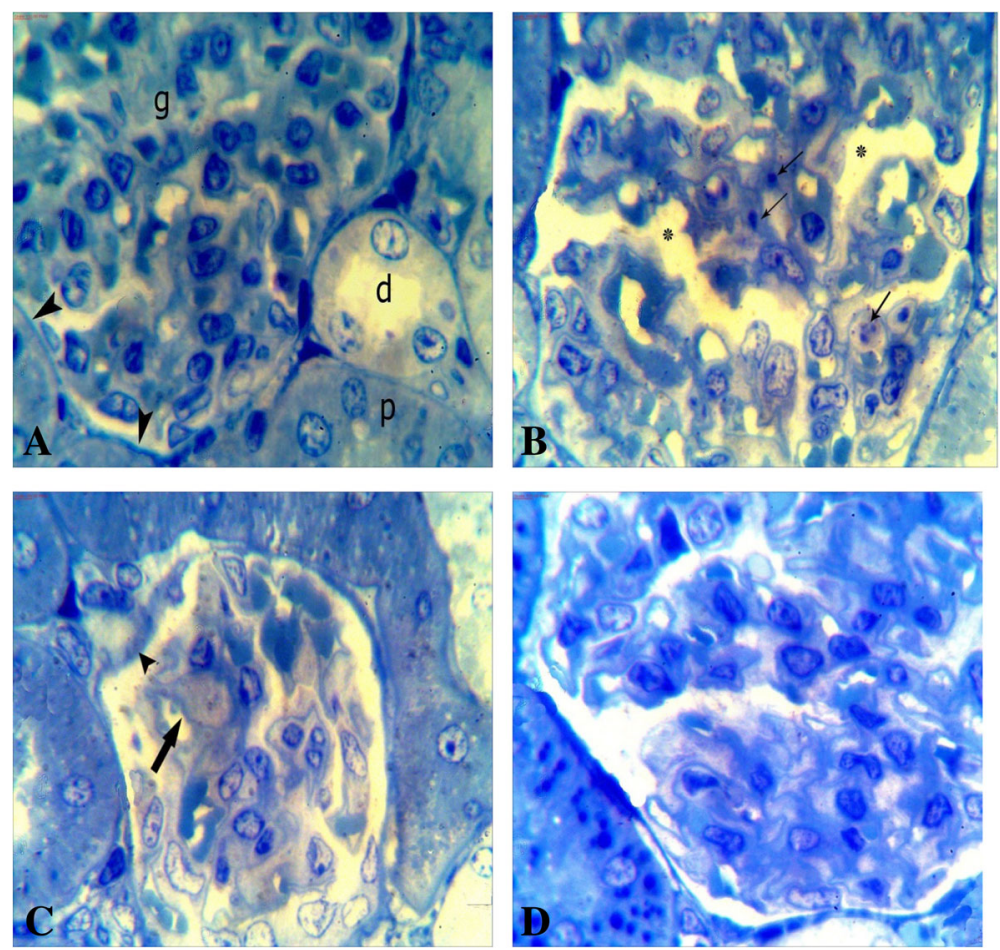

Fig. 3 Photomicrographs of a semithin section in the kidney tissues a A section in control group showing a healthy look of the glomerulus (g), distal tubules (d), and part of a proximal tubule (p), a typically tinny parietal layer of the Bowman's capsule (arrowheads). b A section in CA group showing necrotic cells with an intense and degenerated nuclei (thin arrows), shrinkage and degenerate of the capillary network resulting in widening the spaces (asterisks). c A section in CA group showing a degenerated capsule with thickened of capillary walls (thick arrows) and a decreased in capillary tights, some capsules epithelia cells are degenerated (arrowheads). $\mathbf{d}$ A section in CA + FU group showing more or less healthy looking of the glomerulus (Toluidine blue. $\times 1000$ ).

as hypertension, nephrotoxicity, and hepatotoxicity ((Inselmann et al., 1994); Andrés et al., 2000). In the present study, the levels of MDA and NO in the kidney tissues homogenates increased by CsA administration; this result is in accordance with some previous studies that documented the ROS formation and oxidative status alteration in CsA cytotoxicity (Ezejiofor et al., 2017; Mostafavi-Pour et al., 2008). Further, the association between CsA treatment and the induction of renal failure as well as with the increase of ROS, MDA, and thromboxane levels in the kidney tissue was confirmed in numerous in vivo and in vitro studies (De Arriba et al., 2009; De Hornedo et al., 2007; Wang \& Salahudeen, 1994). Besides that, Krauskopf, Buetler, Nguyen, Macé, and Ruegg (2002) and Galletti et al. (2005) documented the relation between CsA therapy and the decrease of glomerular filtration rate.

The easy contact between CsA and cell organelles is related with the behavior and chemical composition of this drug as confirmed by Wang and Salahudeen (1994) in which CsA is considered as a highly lipophilic agent that facilitates its attachment with organelles membranes especially endoplasmic reticulum and mitochondria which have large amounts of unsaturated fatty acids and have massive total surface area and this make the cells more vulnerable to oxidative stress correlated with CsA. Moreover, the excess production of ROS by CsA can be interpreted through blocking the permeability of transition pore of mitochondria (Nicolli et al., 1996) which led to an increase in the mitochondrial $\mathrm{Ca}^{+2}$ level (Fournier et al., 1987). Also, there is an alteration in the mitochondrial electron transport chain that is consequent in oxidative phosphorylation (Salducci et al., 1992), thus subsequently raise ROS production. Meanwhile, CsA is metabolized by cytochrome P-450 3A that can also induce ROS production alongside the mitochondrial (Serino et al., 1994). Furthermore, CsA treatment caused a variation of haem oxygenase- 1 which is considered as an enzyme related to the redox status of cells (Rezzani, 2006).

The elevation of NO level in the kidney tissue in the present study is in correspondence with a study carried out by Amudha, Josephine, Sudhahar, and Varalakshmi (2007) who found a high concentration of NO in kidney tissue that consequently induced protein oxidation and lipid peroxidation in damaged cells induced by CsA treatment. Also, it has been found that CsA-induced apoptosis in various renal cell lines was mediated by the induction of iNOS via p53 (Amore et al., 2000). 

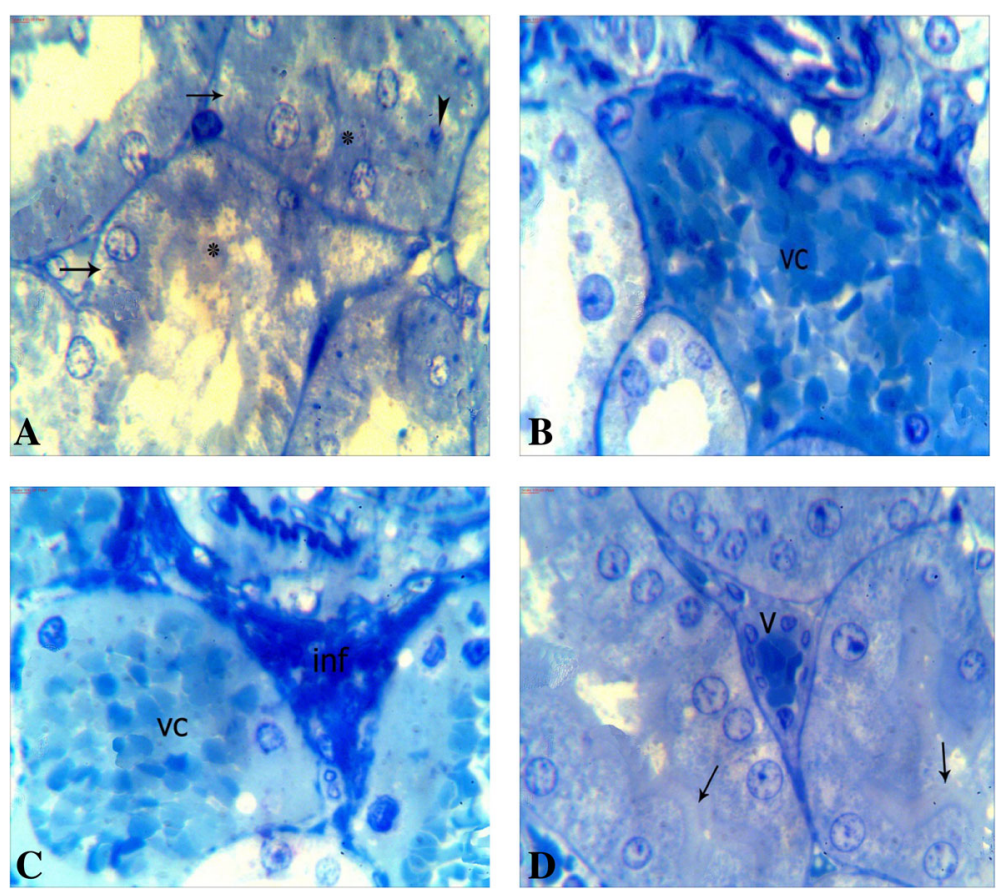

Fig. 4 Photomicrographs of semithin sections of rat kidney tissue. a-c Sections in CA group showing some degenerated epithelial cells of the proximal tubules with a high degree of cytoplasmic vacuolization (thin arrows), destructed of the apical brush border (asterisk), necrosis of some nuclei (arrowhead), as well as a highly vascular congestion (VC) and interstitial infiltration (inf) are present. $\mathbf{d}$ The section in CA + FU group showing proximal tubules with mostly intact epithelial lining and brush border (arrows) and a normal appearance of vessels (v). (Toluidine blue. $\times 1000)$.

In the present study, the levels of GSH and G6PD in kidney tissue were decreased, whereas levels of SOD and CAT were increased by CsA administration. Numbers of previous studies also documented the decrease of kidney GSH level with CsA treatment (Mansour et al., 2002; Yüce et al., 2008). Besides, Lexis et al. (2005) studied the effect of CsA on erythrocyte antioxidant defense. When they administered CsA for 7 days, they found an elevation in the levels of methemoglobin, SOD, and CAT but the levels of GSH and G6PD were decreased. The slight elevation of the SOD level in our study resembles a result of a study carried out by Ebru et al. (2011). Furthermore, Gökçe et al. (2009) documented the increase of SOD and CAT levels in kidney tissue during CsA treatment in which they revealed that an attempt to avoid the free radical increasing induced by CsA. Otherwise, it has been concluded that the decrease of the activity of antioxidants and the increase of lipid peroxidation and oxidative stress in transplanted and non-transplanted human and animals might be due to the direct toxic effect of CsA treatment (Amudha et al., 2006; Türk et al., 2007).

Further, CsA-induced nephrotoxicity has been proposed to be developed through several mechanisms, specifically enhanced sympathetic tenor, renin-angiotensin system activation, increase of endothelin synthesis and inductions of cytochrome P450 enzymes that included in renal microsomes (Dell et al., 2003; Serino et al., 1994; Yoon \& Yang, 2009). Meanwhile, the impairment of arteriolar vessels and glomerular caused by CsA treatment affected the reabsorption efficiency and the excretion of urea, uric acid, and many minerals and ions (Elsayed et al., 2016; Young et al., 1995).

In accordance with the changes of the biochemistry and oxidative parameters in our study, CsA administration also induced marked changes in kidney's tissue such as Malpighian corpuscles hypertrophy with necrotic of glomerulus cells and reduction in Bowman's spaces. Also, there was a renal tubular degeneration that appeared in loss and damage of proximal tubules brush borders, vacuolization, fatty change, and hydropic change. In addition, blood vessels congestion and interstitial infiltration was observed. The study of Rezzani (2004) also noticed severe tubular changes which are in agreement with the finding of our study.

Beside, many histopathological changes in the present study are in agreement with that of Fetouh and Hegazy (2014) who detected some histopathological changes in kidney's tissue followed CsA treatment such as glomeruli shrinkage, Bowman's space expansion, Bowman's capsule thickening, as well as renal tubules cells vacuolization, thickening of basement membrane, and loss of the basal unfolding of the proximal convoluted tubules that associated with disordered of brush border microvilli. The 


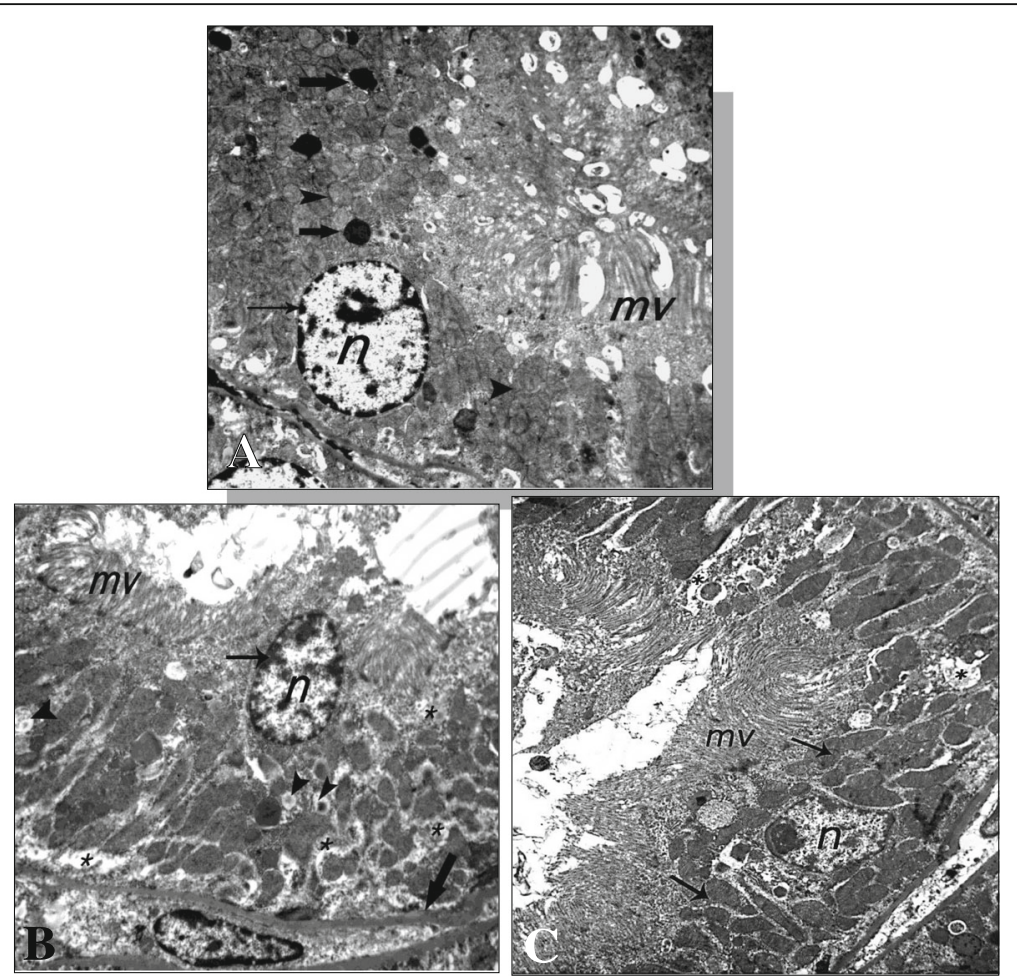

Fig. 5 Electron photomicrography of a part of a proximal convoluted tubule. a (control rat), section showing nucleus (n) containing marginally arranged chromatin material (thin arrows), mitochondria (arrowheads) with intact cristae, many long and dense apical microvilli (mv), and lysosomes (thick arrows). Note the intact cytoplasm. b Section in CA group showing thickening areas of the basement membrane (thick arrow), partial loss of apical microvilli (mv), degenerated nucleus (n) with regressive size, and a high dense chromatin (thin arrow), rarefied cytoplasm (asterisk), some degenerated mitochondria with destructed cristae (arrowheads). c Section in CA + FU group showing: nearly a normal appearance of the nucleus ( $\mathrm{n}$ ) and partial long and dense apical microvilli (mv) as well as rarefied of some parts of cytoplasm (asterisk) can be noted with some healthy parts (arrows). (Uranyl acetate, $\times 3600$ ).

destruction of some mitochondrial cristae in our study is in accordance with that of Fetouh and Hegazy (2014) and with Clarke and Ryan (1999) who also found swelling and rounding of the mitochondria. Further, apoptotic cells that were observed in our study associated CsA treatment also are observed and documented by Justo, Lorz, Sanz, Egido, and Ortiz (2003) who also reported that apoptosis induced by CsA treatment is associated with translocation of BAX (regulator apoptosis factor) to the mitochondria that can lead to caspase-dependent harm on mitochondrial membrane potential. In addition, CsA encourages pro-apoptotic proteins stimulation (Han et al., 2008) that led to endoplasmic reticulum stress resulted in cell death in kidney tissues (Pallet et al., 2008). Furthermore, impairments in the balance of energy metabolism give rise to fluid and electrolyte imbalance which lead to accumulation of excessive fluids in cells and microscopically, the excessive fluids are noted as vacuolization in the cytoplasm (Grub et al., 2000). The vacuolization might be considered as an early stage of cell degeneration (Alden \& Frith, 1991).

Fucoidan has many biological properties in which it acts as an anti-inflammatory, anti-tumor, anti-viral, and antioxidant agent (Cui et al., 2012; Saito et al., 2006; Xue et al., 2001) which attributed to its nature as polyanionic substance that might allow it bind to lots of proteins and exert its important activities (O'Leary et al., 2004).

In the present study, co-treatment with FU was effective in reducing the elevation of the MDA level in the kidney tissue and the level of creatinine in serum, that induced by CsA treatment. FU represented a convenient antioxidant as reported previously by $\mathrm{Hu}$, Geng, Zhang, and Jiang (2001), who documented the minimize oxidants production through scavenging the free radicals and enhancing the antioxidant status by sulfated polysaccharides activation. Furthermore, Zhang et al. (2004) reported the ability of sulfated polysaccharides to prevent oxidative damage in living organisms. Hence, FU can consequently make a protective impact against the chronic renal failure of rats as reported by Zhang, Li, Xu, Niu, and Zhang (2003). FU also prevented the neurotoxic effects of $\beta$-amyloid in rats through blocking the ROS production (Jhamandas et al., 2005) as well as it attenuated the elevation of AST and ALT levels in serum of acute CCl4-induced liver injury (Hayashi et al., 2008). Further, in a study carried out by Han et al. (2015), FU suppressed the oxidative stress in mesenchymal stem 
cells, improved the vascular regeneration of hindlimb ischemia model in murine, repressed the increase of $\mathrm{H}_{2} \mathrm{O}_{2}$, inhibited the stimulation of the pro-apoptotic proteins, and improved the expression of the anti-apoptosis proteins. In the previous study, FU significantly decreased the cellular ROS levels through the activation of the Akt pathway and the increasing of manganese superoxide dismutase expression that resulted in boosted cell survival.

Amazingly, FU extracted from ecklonia cava expressed antioxidant activity, although it was not a flavonoid or polyphenol compound as well as it did not contain benzene rings or conjugated structure (Kim et al., 2014). Ryu and Chung (2016) demonstrate that FU weakens oxidative stress through regulating SOD-1 and HO-1 genes expression via the Nrf2/extracellular signalregulated kinase signaling pathway.

Since FU showed activity as apoptotic stimulator in types of cancer cell (Chen et al., 2014), it might enhance cells regeneration, apoptosis, as well as it eliminates the abnormal and degenerated cells (Irhimeh et al., 2007; Kim et al., 2010; Moon et al., 2011). The mobilizing of stem cells toward the peripheral circulation in baboons and mice was highly improved under the effect of FU (Irhimeh et al., 2007) in which the mechanism of mobilization might be revealed to the capability of FU to inhibit the selectins binding besides its ability to bind SDF-1 and increase the expression of CXCR4 on stem cells (Fermas et al., 2008; Sweeney et al., 2000). So, the present study suggested that the increase of healthy cells in the kidney tissue of FU treated rats might be due to the increase of the mobilization of stem cells, the enhancing of the healthy cells proliferation, and to the elimination of degenerated cells. Recently, Chen et al. (2017) documented that a particular dose of oligo-FU can prevent renal tubulointerstitial fibrosis in a CKD mice model that may be a consequence of the interaction between CD44 and its extracellular ligands. In addition, the low molecular weight of FU, dose-dependent, can inhibit the overexpression of proinflammatory agents and oxidative stress and apoptosis that is induced by albumin overload in vitro study of proximal tubule epithelial cell (Jia et al., 2016). Hence, it could be concluded that FU co-treatment can enhance and adjust the oxidative stress status in the kidney of CsAtreated rats, and it could partially ameliorate the disorder of the kidney functions and repair the histopathological aspects that result by CsA treatment.

\section{Conclusion}

Our results reveal that fucoidan which is purified from brown algae possessed a respectable antioxidant activity against kidney injury induced by cyclosporine A which is used as immunosuppressive therapy. Hence, the present study supports the renoprotective effect of fucoidan as it adjustment the oxidative stress condition and ameliorates the injury of the kidney.

\section{Abbreviations}

CAT: Catalase; CsA: Cyclosporine A; FU: Fucoidan; G6PD: Glucose 6 phosphate dehydrogenase; GSH: Glutathione reduced;

MDA: Malondialdehyde; NO: Nitric oxide; OS: Oxidative stress; ROS: Reactive oxygen species; SOD: Superoxide dismutase

\section{Acknowledgments}

The authors are grateful to OWSD and Sid for the financial support to this study. Also, authors are thankful to the Department of Biology, Science Faculty of Assuit University for the provided facilities during carrying out this work.

\section{Consent to participate or publication}

Not applicable.

\section{Funding}

The first author was funded by OWSD Fellowship awarded by the Organization for Woman in Sciences and the Development World and Sid (Swedish International Development Cooperation Agency). The funding was used for purchasing the respective chemicals for the research work and other required equipment of study.

\section{Availability of data and materials}

It is available when request.

\section{Declarations}

This manuscript is an original investigation as well as it is not submitted elsewhere for publication.

\section{Authors' contribution}

BYHA-K contributed to the samples processing, preparation, data analysis, and manuscript writing and editing. NMHAH and HSAG contributed to manuscript writing, correction, and preparation. All authors read and approved the final manuscript.

\section{Ethics approval}

All experiments followed protocols approved by the Institutional Animal Care and Life Committee, Assiut University and and the Guidelines for Ethical Conduct in the Care and Use of Animals provided by American Association of Psychologists.

\section{Competing interests}

The authors declare that they have no competing interests.

\section{Publisher's Note}

Springer Nature remains neutral with regard to jurisdictional claims in published maps and institutional affiliations.

Received: 10 December 2018 Accepted: 24 May 2019

Published online: 11 June 2019

\section{References}

Alden, C. L., \& Frith, C. H. (1991). Urinary system. In W. M. Haschek, \& C. G. Rousseaux (Eds.), Handbook of Toxicologic pathology, (pp. 315-387).

Amore, A., Emancipator, S. N., Cirina, P., Conti, G., Ricotti, E., Bagheri, N., \& Coppo, R. (2000). Nitric oxide mediates cyclosporine-induced apoptosis in cultured renal cells. Kidney International, 57(4), 1549-1559.

Amudha, G., Josephine, A., Sudhahar, V., \& Varalakshmi, P. (2007). Protective effect of lipoic acid on oxidative and peroxidative damage in cyclosporine Ainduced renal toxicity. International Immunopharmacology, 7(11), 1442-1449.

Amudha, G., Josephine, A., \& Varalakshmi, P. (2006). Role of lipoic acid in reducing the oxidative stress induced by cyclosporine A. Clinica Chimica Acta, 372(1-2), 134-139.

Andrés, D., Sanz, N., Zaragoza, A., Alvarez, A.M. \& Cascales, M. (2000). Changes in antioxidant defense systems induced by cyclosporine $A$ in cultures of hepatocytes from 2-and 12-month-old rats. Biochemical Pharmacology, 59(9), 1091-1100.

Anjaneyulu, M., Tirkey, N., \& Chopra, K. (2003). Attenuation of cyclosporineinduced renal dysfunction by catechin: Possible antioxidant mechanism. Renal Failure, 25(5), 691-707. 
Balboa, E. M., Conde, E., Moure, A., Falqué, E., \& Domínguez, H. (2013). In vitro antioxidant properties of crude extracts and compounds from brown algae. Food Chemistry, 138(2-3), 1764-1785.

Bancroft, J. D., \& Gamble, M. (Eds.) (2008). Theory and practice of histological techniques. Elsevier Health Sciences.

Barros, E. J., Boim, M. A., Ajzen, H., Ramos, O. L., \& Schor, N. (1987). Glomerular hemodynamics and hormonal participation on cyclosporine nephrotoxicity. Kidney International, 32(1), 19-25.

Beers, R. F., \& Sizer, I. W. (1952). A spectrophotometric method for measuring the breakdown of hydrogen peroxide by catalase. Journal Biological Chemistry, 195(1), 133-140.

Beutler, E. (1963). Improved method for determination of blood glutathione. Journal Lab Clinical Medicine, 61(5), 882-888.

Bilan, M. I., Grachev, A. A., Ustuzhanina, N. E., Shashkov, A. S., Nifantiev, N. E., \& Usov, A. I. (2002). Structure of a fucoidan from the brown seaweed Fucus evanescens C. Ag. Carbohydrate Research, 337(8), 719-730.

Chen, C. H., Sue, Y. M., Cheng, C. Y., Chen, Y. C., Liu, C. T., Hsu, Y. H., ... Chen, T. H. (2017). Oligo-fucoidan prevents renal tubulointerstitial fibrosis by inhibiting the CD44 signal pathway. Scientific Reports, 7, 40183.

Chen, S., Zhao, Y., Zhang, Y., \& Zhang, D. (2014). Fucoidan induces cancer cell apoptosis by modulating the endoplasmic reticulum stress cascades. PLOS One, 9(9), e108157.

Clarke, H., \& Ryan, M. P. (1999). Cyclosporine A-induced alterations in magnesium homeostasis in the rat. Life Sciences, 64(15), 1295-1306.

Cui, Y. Q., Jia, Y. J., Zhang, T., Zhang, Q. B., \& Wang, X. M. (2012). Fucoidan protects against lipopolysaccharide-induced rat neuronal damage and inhibits the production of proinflammatory mediators in primary microglia. CNS Neuroscience \& Therapeutics, 18(10), 827-833.

De Arriba, G., de Hornedo, J. P., Rubio, S. R., Fernández, M. C., Martínez, S. B., Camarero, M. M., \& Cid, T. P. (2009). Vitamin E protects against the mitochondrial damage caused by cyclosporin A in LLC-PK1 cells. Toxicology and Applied Pharmacology, 239(3), 241-250.

De Hornedo, J. P., De Arriba, G., Fernández, M. C., Benito, S., \& Cid, T. P. (2007). Cyclosporin A causes oxidative stress and mitochondrial dysfunction in tubular renal cells. Nefrologia, 27(5), 565-573.

De Mattos, A. M., Olyaei, A. J., \& Bennett, W. M. (2000). Nephrotoxicity of immunosuppressive drugs: Long-term consequences and challenges for the future. American Journal of Kidney Diseases, 35(2), 333-346.

Dell, K., Böhler, T., Gaedeke, J., Budde, K., Neumayer, H. H., \& Waiser, J. (2003). Impact of PGE1 on cyclosporine $A$ induced up-regulation of TGF- $\beta 1$, its receptors, and related matrix production in cultured mesangial cells. Cytokine, 22(6), 189-193.

Ding, A. H., Nathan, C. F., \& Stuehr, D. J. (1988). Release of reactive nitrogen intermediates and reactive oxygen intermediates from mouse peritoneal macrophages. Comparison of activating cytokines and evidence for independent production. The Journal of Immunology, 141(7), 2407-2412.

Durak, I., Kaçmaz, M., Çimen, M. B., Büyükkoçak, S., Elgün, S., \& Öztürk, H. S. (2002). The effects of cyclosporine on antioxidant enzyme activities and malondialdehyde levels in rabbit hepatic tissues. Transplant Immunology, 10(4), 255-258.

Ebru, U., Burak, U., Arif, K., Derya, A., NuketBavbek, R., Efkan, U., ... Ali, A. (2011). Protective effect of erdosteine on cyclosporine-induced chronic nephrotoxicity in rats. Nephro-Urology Monthly, 2011(4, Autumn), 280-284.

Eldien, H. M. S., Omar, H. E. D. M., Badary, M. S., \& Al-Khatib, B. Y. (2012). The possible protective and therapeutic roles of fucoidan in cyclosporineinduced histological changes in the bone marrow and spleen in rats. Egyptian Journal of Histology, 35(3), 383-397.

Elsayed, A. S. I., Bayomy, M. F. F., \& Azab, A. E. (2016). Effect of acute and chronic treatment of cyclosporin A on liver and kidney functions in rats. Journal of Applied Pharmaceutical Science, 6(3), 116-119.

Ezejiofor, A. N., Udowelle, N. A., \& Orisakwe, O. E. (2017). Nephroprotective and antioxidant effect of aqueous leaf extract of Costus Afer Ker gawl on cyclosporin-a (Csa) induced nephrotoxicity. Clinical Phytoscience, 2(1), 11.

Fermas, S., Gonnet, F., Sutton, A., Charnaux, N., Mulloy, B., Du, Y., ... Daniel, R. (2008). Sulfated oligosaccharides (heparin and fucoidan) binding and dimerization of stromal cell-derived factor-1 (SDF-1/CXCL 12) are coupled as evidenced by affinity CE-MS analysis. Glycobiology, 18(12), 1054-1064.

Fetouh, F. A., \& Hegazy, A. A. (2014). Effect of cyclosporine A on the kidney of rabbit: A light and ultrastructural study. International Journal of Anatomy and Research, 2(4), 768-776.

Fournier, N., Ducet, G., \& Crevat, A. (1987). Action of cyclosporine on mitochondrial calcium fluxes. Journal of Bioenergetics and Biomembranes, 19(3), 297-303.
Galletti, P., Di Gennaro, C. I., Migliardi, V., Indaco, S., Della Ragione, F., Manna, C., ... Zappia, V. (2005). Diverse effects of natural antioxidants on cyclosporin cytotoxicity in rat renal tubular cells. Nephrology Dialysis Transplantation, 20(8), 1551-1558.

Gökçe, A., Oktar, S., Yönden, Z., Aydın, M., Illhan, S., Özkan, O. V., ... Yalçınkaya, F. R. (2009). Protective effect of caffeic acid phenethyl ester on cyclosporine Ainduced nephrotoxicity in rats. Renal Failure, 31(9), 843-847.

Grub, S., Persohn, E., Trommer, W. E., \& Wolf, A. (2000). Mechanisms of cyclosporine A-induced apoptosis in rat hepatocyte primary cultures. Toxicology and Applied Pharmacology, 163(3), 209-220.

Gupta, P. D. (1983). Ultrastructural study on semithin section. Sci Tools, 30(1), 6-7.

Han, S. W., Li, C., Ahn, K. O., Lim, S. W., Song, H. G., Jang, Y. S., ... Kim, S. H. (2008), Prolonged endoplasmic reticulum stress induces apoptotic cell death in an experimental model of chronic cyclosporine nephropathy. American Journal of Nephrology, 28(5), 707-714.

Han, Y. S., Lee, J. H., Jung, J. S., Noh, H., Baek, M. J., Ryu, J. M., ... Lee, S. H. (2015). Fucoidan protects mesenchymal stem cells against oxidative stress and enhances vascular regeneration in a murine hindlimb ischemia model. International Journal of Cardiology, 198, 187-195.

Harper, J. I., Berth-Jones, J., Camp, R. D. R., Dillon, M. J., Finlay, A. Y., Holden, C. A., ... Veys, P. A. (2001). Cyclosporin for atopic dermatitis in children. Dermatology, 203(1), 3-6.

Hayashi, S., Itoh, A., Isoda, K., Kondoh, M., Kawase, M., \& Yagi, K. (2008). Fucoidan partly prevents CCl4-induced liver fibrosis. European Journal of Pharmacology, 580(3), 380-384.

Herrero, J. I., Quiroga, J., Sangro, B., Beloqui, O., Pardo, F., Cienfuegos, J. A., \& Prieto, J. (2000). Hyperhomocysteinemia in liver transplant recipients: Prevalence and multivariate analysis of predisposing factors. Liver Transplantation, 6(5), 614-618.

Ho, S., Clipstone, N., Timmermann, L., Northrop, J., Graef, I., Fiorentino, D., .. Crabtree, G. R. (1996). The mechanism of action of cyclosporin A and FK506. Clinical Immunology and Immunopathology, 80(3), S40-S45.

Hu, J. F., Geng, M. Y., Zhang, J. T., \& Jiang, H. D. (2001). An in vitro study of the structure-activity relationships of sulfated polysaccharide from brown algae to its antioxidant effect. Journal of Asian Natural Products Research, 3(4), 353-358.

Inselmann, G., Lawerenz, H. U., Nellessen, U., \& Heidemann, H. T. (1994). Enhancement of cyclosporin A induced hepato-and nephrotoxicity by glutathione depletion. European Journal of Clinical Investigation, 24(5), 355-359.

Irhimeh, M. R., Fitton, J. H., \& Lowenthal, R. M. (2007). Fucoidan ingestion increases the expression of CXCR4 on human CD34+ cells. Experimental Hematology, 35(6), 989-994.

Jhamandas, J. H., Wie, M. B., Harris, K., MacTavish, D., \& Kar, S. (2005). Fucoidan inhibits cellular and neurotoxic effects of $\beta$-amyloid $(A \beta)$ in rat cholinergic basal forebrain neurons. European Journal of Neuroscience, 21(10), 2649-2659.

Jia, Y., Sun, Y., Weng, L., Li, Y., Zhang, Q., Zhou, H., \& Yang, B. (2016). Low molecular weight fucoidan protects renal tubular cells from injury induced by albumin overload. Scientific Reports, 6, 31759.

Josephine, A., Nithya, K., Amudha, G., Veena, C. K., Preetha, S. P., \& Varalakshmi, P. (2008). Role of sulphated polysaccharides from Sargassum Wightii in cyclosporine A-induced oxidative liver injury in rats. BMC Pharmacology, 8(1), 4.

Josephine, A., Veena, C. K., Amudha, G., Preetha, S. P., \& Varalakshmi, P. (2006). Evaluating the effect of sulphated polysaccharides on cyclosporine a induced oxidative renal injury. Molecular and Cellular Biochemistry, 287(1-2), 101-108.

Justo, P., Lorz, C., Sanz, A., Egido, J., \& Ortiz, A. (2003). Intracellular mechanisms of Cyclosporin A-induced tubular cell apoptosis. Journal of the American Society of Nephrology, 14(12), 3072-3080.

Kim, E. A., Lee, S. H., Ko, C. I., Cha, S. H., Kang, M. C., Kang, S. M., ... Kang, N. (2014). Protective effect of fucoidan against AAPH-induced oxidative stress in zebrafish model. Carbohydrate Polymers, 102, 185-191.

Kim, E. J., Park, S. Y., Lee, J. Y., \& Park, J. H. Y. (2010). Fucoidan present in brown algae induces apoptosis of human colon cancer cells. BMC Gastroenterology, 10(1), 96.

Krauskopf, A., Buetler, T. M., Nguyen, N. S., Macé, K., \& Ruegg, U. T. (2002). Cyclosporin A-induced free radical generation is not mediated by cytochrome P-450. British Journal of Pharmacology, 135(4), 977-986.

Kwak, J. Y. (2014). Fucoidan as a marine anticancer agent in preclinical development. Marine Drugs, 12(2), 851-870.

Laskow, D. A., Curtis, J. J., Luke, R. G., Julian, B. A., Jones, P., Deierhoi, M. H., ... Diethelm, A. G. (1990). Cyclosporine-induced changes in glomerular filtration rate and urea excretion. American. Journal. Medical., 88(5), 497-502. 
Lexis, L. A., Richards, R. S., Fassett, R. G., \& Coombes, J. S. (2005). Cyclosporine Ainduced changes to erythrocyte redox balance is time course-dependent. Basic \& Clinical Pharmacology \& Toxicology, 97(3), 135-140.

Li, B., Lu, F., Wei, X., \& Zhao, R. (2008). Fucoidan: Structure and bioactivity. Molecules, 13(8), 1671-1695.

Lowry, O. H., Rosebrough, N. J., Farr, A. L., \& Randall, R. J. (1951). Protein measurement with the Folin phenol reagent. Journal of Biological Chemistry, 193(1), 265-275.

Mansour, M., Daba, M. H., Gado, A., Al-Rikabi, A., \& Al-Majed, A. (2002). Protective effect of L-arginine against nephrotoxicity induced by cyclosporine in normal rats. Pharmacological Research, 45(6), 441-446.

Matsuda, S., \& Koyasu, S. (2000). Mechanisms of action of cyclosporine. Immunopharmacology, 47(2-3), 119-125.

Misra, H. P., \& Fridovich, I. (1972). The role of superoxide anion in the autoxidation of epinephrine and a simple assay for superoxide dismutase Journal of Biological Chemistry, 247(10), 3170-3175.

Moon, I. S., So, J. H., Jung, Y. M., Lee, W. S., Kim, E. Y., Choi, J. H., ... Choi, J. Y. (2011). Fucoidan promotes mechanosensory hair cell regeneration following amino glycoside-induced cell death. Hearing Research, 282(1-2), 236-242.

Mostafavi-Pour, Z., Zal, F., Monabati, A., \& Vessal, M. (2008). Protective effects of a combination of quercetin and vitamin $E$ against cyclosporine A-induced oxidative stress and hepatotoxicity in rats. Hepatology Research, 38(4), 385-392.

Nicolli, A., Basso, E., Petronilli, V., Wenger, R. M., \& Bernardi, P. (1996). Interactions of cyclophilin with the mitochondrial inner membrane and regulation of the permeability transition pore, a cyclosporin A-sensitive channel. Journal of Biological Chemistry, 271(4), 2185-2192.

Ohkawa, H., Ohishi, N., \& Yagi, K. (1979). Assay for lipid peroxides in animal tissues by thiobarbituric acid reaction. Analytical Biochemistry, 95(2), 351-358.

O'Leary, R., Rerek, M., \& Wood, E. J. (2004). Fucoidan modulates the effect of transforming growth factor (TGF)- $\beta 1$ on fibroblast proliferation and wound repopulation in vitro models of dermal wound repair. Biological and Pharmaceutical Bulletin, 27(2), 266-270.

Omar, H. E. D. M., Eldien, H. M. S., Badary, M. S., Al-Khatib, B. Y., \& Abd Elgaffar, S. K. (2013). The immunomodulating and antioxidant activity of fucoidan on the splenic tissue of rats treated with cyclosporine A. The Journal of Basic \& Applied Zoology, 66(5), 243-254.

Pallet, N., Bouvier, N., Legendre, C., Gilleron, J., Codogno, P., Beaune, P., ... Anglicheau, D. (2008). Autophagy protects renal tubular cells against cyclosporine toxicity. Autophagy, 4(6), 783-791.

Park, P. J., Heo, S. J., Park, E. J., Kim, S. K., Byun, H. G., Jeon, B. T., \& Jeon, Y. J. (2005). Reactive oxygen scavenging effect of enzymatic extracts from Sargassum thunbergii. Journal of Agricultural and Food Chemistry, 53(17), 6666-6672.

Rezzani, R. (2004). Cyclosporine a and adverse effects on organs: Histochemical studies. Progress in Histochemistry and Cytochemistry, 39(2), 85-128.

Rezzani, R. (2006). Exploring cyclosporine A-side effects and the protective roleplayed by antioxidants: The morphological and immunohistochemical studies. Histology and Histopathology, 21(1/3), 301-316.

Ryu, M. J., \& Chung, H. S. (2016). Fucoidan reduces oxidative stress by regulating the gene expression of HO-1 and SOD-1 through the Nrf2/ERK signaling pathway in HaCaT cells. Molecular Medicine Reports, 14(4), 3255-3260.

Saito, A., Yoneda, M., Yokohama, S., Okada, M., Haneda, M., \& Nakamura, K. (2006). Fucoidan prevents concanavalin A-induced liver injury through induction of endogenous IL-10 in mice. Hepatology Research, 35(3), 190-198.

Salducci, M. D., Chauvet-Monges, A. M., Berland, Y., Dussol, B., Elsen, R., \& Crevat, A. (1992). The restoration of ATP synthesis may explain the protective effect of calcium antagonists against cyclosporine $A$ nephrotoxicity. Life Sciences, 50(26), 2053-2058.

Serino, F., Grevel, J., Napoli, K. L., Kahan, B. D., \& Strobel, H. W. (1994). Oxygen radical formation by the cytochrome $\mathrm{P} 450$ system as a cellular mechanism for cyclosporine toxicity. Transplantation Proceedings, 26(5), 2916-2917.

Slattery, C., Campbell, E., McMorrow, T., \& Ryan, M. P. (2005). Cyclosporine A induced renal fibrosis: A role for epithelial-mesenchymal transition. The American Journal of Pathology, 167(2), 395-407.

Sweeney, E. A., Priestley, G. V., Nakamoto, B., Collins, R. G., Beaudet, A. L., \& Papayannopoulou, T. (2000). Mobilization of stem/progenitor cells by sulfated polysaccharides does not require selectin presence. Proceedings of the National Academy of Sciences, 97(12), 6544-6549.

Tedesco, D., \& Haragsim, L. (2012). Cyclosporine: A review. Journal of transplantation article in press.

Tsai, C. S., \& Chen, Q. (1998). Purification and kinetic characterization of hexokinase and glucose-6-phosphate dehydrogenase from Schizosaccharomyces pombe. Biochemistry and Cell Biology, 76(1), 107-113.
Türk, G., Ateşşahin, A., Sönmez, M., Yüce, A., \& Çeribaşi, A. O. (2007). Lycopene protects against cyclosporine A-induced testicular toxicity in rats. Theriogenology, 67(4), 778-785.

Uz, E., Bayrak, O., Uz, E., Kaya, A., Bayrak, R., Uz, B., ... Akcay, A. (2008). Nigella sativa oil for prevention of chronic cyclosporine nephrotoxicity: An experimental model. American Journal of Nephrology, 28(3), 517-522.

Veena, C. K., Josephine, A., Preetha, S. P., Varalakshmi, P., \& Sundarapandiyan, R. (2006). Renal peroxidative changes mediated by oxalate: The protective role of fucoidan. Life Sciences, 79(19), 1789-1795.

Wang, C., \& Salahudeen, A. K. (1994). Cyclosporine nephrotoxicity: Attenuation by an antioxidant-inhibitor of lipid peroxidation in vitro and in vivo. Transplantation, 58(8), 940-946.

Xue, C. H., Fang, Y., Lin, H., Chen, L., Li, Z. J., Deng, D., \& Lu, C. X. (2001). Chemical characters and antioxidative properties of sulfated polysaccharides from Laminaria japonica. Journal of Applied Phycology, 13(1), 67-70.

Yoon, H. E., \& Yang, C. W. (2009). Established and newly proposed mechanisms of chronic cyclosporine nephropathy. The Korean Journal of Internal Medicine, 24(2), 81-92.

Young, B. A., Burdmann, E. A., Johnson, R. J., Andoh, T., Bennett, W. M., Couser, W. G., \& Alpers, C. E. (1995). Cyclosporine A induced arteriolopathy in a rat model of chronic cyclosporine nephropathy. Kidney International, 48(2), 431-438.

Young, D. S. (1990). Effects of drugs on clinical laboratory tests, (3rd ed., ). Washington, DC: AACC Press.

Yüce, A., Ateşşahin, A., \& Çeribaşı, A. O. (2008). Amelioration of cyclosporine Ainduced renal, hepatic and cardiac damages by Ellagic acid in rats. Basic \& Clinical Pharmacology \& Toxicology, 103(2), 186-191.

Zhang, Q., Li, N., Liu, X., Zhao, Z., Li, Z., \& Xu, Z. (2004). The structure of a sulfated galactan from Porphyra haitanensis and its in vivo antioxidant activity. Carbohydrate Research, 339(1), 105-111.

Zhang, Q., Li, Z., Xu, Z., Niu, X., \& Zhang, H. (2003). Effects of fucoidan on chronic renal failure in rats. Planta Medica, 69(06), 537.

\section{Submit your manuscript to a SpringerOpen ${ }^{\circ}$ journal and benefit from:}

- Convenient online submission

Rigorous peer review

- Open access: articles freely available online

High visibility within the field

- Retaining the copyright to your article

Submit your next manuscript at $\boldsymbol{s}$ springeropen.com 